\title{
Nem invisíveis, nem visados: inovação, direitos humanos e vulnerabilidade de grupos no contexto da Covid-19
}

\author{
Nether invisible nor targeted: innovation, human rights and group \\ vulnerability in the Covid-19 context
}

\author{
Joana de Souza Machadoa,* \\ Sergio Marcos Carvalho de Ávila Negria \\ Carolina Fiorini Ramos Giovaninia (iD)
}

\begin{abstract}
RESUMO: O presente trabalho a partir de método reconstrutivo de abordagem, de perfil exploratório, realiza uma análise de tecnologias e inovações utilizadas no enfrentamento da pandemia da COVID-19, problematizando, a partir do aporte teórico de Judith Butler sobre precariedade e condição precária, a alocação diferencial dos impactos dessas medidas, considerando desafios técnicos, jurídicos e éticos. Com o detalhamento de tecnologias empregadas no combate à pandemia, combinado a análise de casos concretos, busca-se demonstrar a falta de proporcionalidade de medidas que vêm sendo naturalizadas no enfrentamento da crise, especialmente quanto a direitos de grupos politicamente vulneráveis, ora invisibilizados, ora excessivamente expostos e visados. Em conclusão, aponta-se a necessidade de construção de alternativas mais sensíveis às distintas camadas de vulnerabilidade a que as pessoas, individual e coletivamente, estão submetidas.
\end{abstract}

Palavras-chave: Inovação; Direitos Humanos; Vulnerabilidade; Covid-19.

ABSTRACT: The present work, based on a reconstructive approach method, with an exploratory profile, analyzes technologies and innovations used to face the COVID-19 pandemic, problematizing, based on Judith Butler's theoretical contribution on precariousness and precarity, the differential allocation of these measures impacts, considering technical, legal, and ethical challenges. Detailing the technologies used to fight the pandemic, combined with the analysis of concrete cases, we seek to demonstrate the lack of proportionality of measures that have been naturalized in the face of the crisis, especially regarding the rights of groups politically vulnerable, either invisible or overexposed and targeted. In conclusion, it points out the need to build alternatives are more sensitive to the different layers of vulnerability to which people, individually and collectively, are subjected.

Keywords: Innovation; Human Rights; Vulnerability; Covid-19.

\footnotetext{
a Faculdade de Direito, Universidade Federal de Juiz de Fora, Juiz de Fora, MG, Brasil.

*Correspondência para/correspondence to: Joana de Souza Machado. E-mail: joana.machado@ufjf.edu.br. Endereço institucional: Faculdade de Direito - Universidade Federal de Juiz de Fora; Rua José Lourenço Kelmer, s/n - Campus Universitário - Bairro São Pedro - CEP: 36036-900 - Juiz de Fora - MG.
}

Recebido em/Received: 01/09/2020; Aprovado em/Approved:30/11/2020.

Artigo publicado em acesso aberto sob licença $\mathrm{CC}$ BY 4.0 Internacional $@(1)$ 


\section{INTRODUÇÃO}

Com a pandemia da COVID-19, mergulhamos em profunda crise sanitária de escala global. Por seu amplo impacto, o vírus pode soar democrático ${ }^{1}$, abastecendo o imaginário popular sobre a morte ${ }^{2}$ e sobre a batalha contra ela, como eventos de equiparação entre as mais diversas pessoas e os mais diversos territórios.

O mergulho é coletivo, é global. Aproxima experiências, dilemas, desafios e tentações. Mas cada país se depara com os limites de seu próprio repertório; assim como cada pessoa se depara com as suas condições objetivas e subjetivas de existência, com a sua própria capacidade de agir, historicamente condicionada e estruturada, filtrando/acirrando os impactos da crise.

Encontram-se em curso, no combate à pandemia, diversas experiências pautadas no uso de tecnologias para a ampla coleta de dados: monitoramento das pessoas em quarentena a partir de dados de geolocalização; rastreamento rigoroso do percurso de pessoas infectadas (contact tracing), com utilização de dados de smartphones; envio maciço de mensagens de SMS com a completa identificação dos lugares transitados por pessoas contaminadas.

O diálogo entre a ciência e a política acena mesmo para a necessidade de adoção de diversas medidas restritivas de direitos e garantias, individuais e coletivos, na construção de políticas públicas de contenção do vírus. Para muitos Estados, isso significa ter que repactuar com a sociedade esse conjunto de direitos, ainda que em caráter excepcional e provisório.

Trata-se de um teste imenso, no qual Estados são desafiados a adotar medidas à altura dessa batalha sanitária, e, em cenários (ainda que apenas formalmente) mais democráticos, a justificar a adequação e a necessidade dessas medidas restritivas de direitos; e a sociedade, mesmo ocupada de sobreviver à crise, a avaliar essa justificativa, com atenção a possíveis abusos e riscos de legados autoritários.

O presente trabalho, a partir de método reconstrutivo de abordagem, de perfil exploratório, propõe-se justamente a analisar inovações e tecnologias de coleta de dados utilizadas no enfrentamento da pandemia da COVID-19, problematizando, a partir do aporte teórico de Judith Butler ${ }^{3}$ sobre precariedade e condição precária, riscos e impactos dessas medidas para grupos de vulnerabilidade politicamente induzida, considerando desafios técnicos, jurídicos e éticos.

Para tanto, o trabalho se estrutura a partir de três eixos principais, profundamente imbricados: normativo, tecnológico e ético/político. No plano normativo (item 1), procura-se iluminar a ausência de incompatibilidade entre normativas recentes de proteção de dados e o uso de dados pessoais no combate à pandemia, destacando-se o descolamento da proteção de dados, enquanto direito fundamental, do sentido

\footnotetext{
1 "Esse vírus é democrático, e não distingue entre ricos e pobres ou entre agentes estatais e cidadãos ordinários" (Tradução nossa). Trecho do discurso do Vice Ministro da Saúde do Irã, Iraj Harirchi, ao comentar a sua própria infecção pela COVID-19. Disponível em: https://www.theguardian.com/world/2020/feb/25/irans-deputy-health-minister-i-havecoronavirus Acesso em 02 de abr de 2020.

2 Tão bem retratado no campo literário, como nas obras de Saramago, Suassuna, entre outros, a exemplo da fala de Chicó: "[...] cumpriu sua sentença e encontrou-se com o único mal irremediável, aquilo que é a marca de nosso estranho destino sobre a terra, aquele fato sem explicação que iguala tudo o que é vivo num só rebanho de condenados, porque tudo o que é vivo morre". SUASSUNA, Ariano. Auto da Compadecida. 10. ed. São Paulo: Agir Editora, 1973, p. SARAMAGO, José. As intermitências da morte. São Paulo: Companhia das Letras, 2005.

3 BUTLER, Judith. Quadros de Guerra: quando a vida é passível de luto? Tradução de Sérgio Lamarão e Arnaldo Marques da Cunha. Rio de Janeiro: Civilização Brasileira, 2016, p. 33.
} 
tradicional de privacidade, e sua consequente conexão com outras liberdades democráticas. No plano tecnológico (itens 2 e 3), procura-se detalhar algumas das principais medidas de utilização de dados pessoais no combate à pandemia, a fim de que se permita uma mais adequada visualização e avaliação de riscos impostos ao exercício de outros direitos. No plano ético/político (item 4), a avaliação desses riscos é filtrada pelo referencial teórico usado, demonstrando-se que há uma alocação desigual e especialmente desproporcional dos impactos da vigilância e da negação de direitos para grupos que historicamente experimentam vulnerabilidades, politicamente induzidas ou ampliadas.

Investiga-se, assim, a hipótese de que embora essa alocação desigual não seja inaugurada por crises, como a da pandemia da COVID-19, acirra-se em contextos de emergência, e demanda enfrentamentos que transcendem em muito o campo jurídico.

\section{INOVAÇÃO E COLETA DE DADOS NO COMBATE À PANDEMIA}

O presente trabalho busca escapar ao binarismo maniqueísta que comumente acompanha as abordagens de inovações e tecnologias, taxando-as como boas ou ruins em si. Isso não significa, porém, dizer que as tecnologias sejam neutras. Artefatos tecnológicos podem ser influenciados por razões políticas ${ }^{4}$ e, ao mesmo tempo, impactar politicamente a sociedade. Podem gerar repercussões éticas e jurídicas nem sempre antecipáveis ou bem calculadas no momento em que são desenvolvidos. O raciocínio se aplica especialmente em contextos de emergência, em que as avaliações são aceleradas.

No enfrentamento da pandemia, dados passam a ser trunfos contra a COVID-19. São amplamente demandados e usados na construção de modelos matemáticos voltados à compreensão do histórico de mutação do vírus; à projeção de impacto de medidas de contenção do contágio, como o isolamento social; à simulação de cenários para uma adequada gestão da infraestrutura hospitalar; entre outras estratégias de política sanitária.

Ao contrário do que se possa imaginar, o direito à privacidade não desautoriza automaticamente essas práticas. Na era da informação, a proteção de dados pessoais (dados relacionados a pessoas identificadas ou identificáveis) ${ }^{5}$ descola-se do discurso tradicional, estático, de privacidade - da ideia de sigilo, de segredo. Aproxima-se de uma perspectiva mais dinâmica, da noção de controle sobre o uso dos próprios dados. ${ }^{6}$ Nesse sentido, a proteção de dados é entendida também como importante termômetro às democracias, às condições de exercício de outros direitos

\footnotetext{
${ }^{4}$ Atento à dimensão política dos artefatos tecnológicos, Winner se vale do exemplo de construções urbanas de Robert Moses na cidade de Nova lorque, projetadas para fisicamente impedir transportes públicos coletivos em áreas mais nobres da cidade e, via de consequência, segregar a população negra, usuária então mais predominante desse meio de locomoção. WINNER, Langdon. Do artifacts have politics? Daedalus. Vol. 109, n. 01. Modern technology: Problem or opportunity (Winter, 1980). p. 121-136. Disponível em: https://www.cc.gatech.edu/ beki/cs4001/Winner.pdf Acesso em 15 jun 2020.

5 Bioni aponta para a existência de dois modelos de conceituação, que são responsáveis por definir a moldura normativa: em um modelo expansionista, os dados são definidos como informações relacionadas à pessoa identificada ou identificável, evidenciando um vínculo indireto; e no modelo reducionista, o dado pessoal é a informação de pessoa identificada, isto é, uma pessoa específica, desse modo, busca um vínculo direto entre indivíduo e informação. A LGPD e o RGPD definem o dado pessoal a partir do modelo expansionista de conceituação, ou seja, o dado pessoal é uma informação relacionada à pessoa natural identificada ou identificável. BIONI, B. R. Proteção de Dados pessoais: a função e os limites do consentimento. Rio de Janeiro. Forense, 2019.

${ }^{6}$ DONEDA, D. Da privacidade à proteção de dados pessoais: elementos da lei geral de proteção de dados. 2. ed. São Paulo: Thomson Reuters Brasil, 2019.
} 
fundamentais, como liberdade de expressão, liberdade de associação, liberdade profissional, sindical, direito à igualdade, e não apenas aos direitos de privacidade e intimidade.

Diz, portanto, menos respeito a "se" os dados pessoais são/serão usados, do que ao conjunto de perguntas "para quê?", "como?", e "por quem?" esses dados são/serão usados. A proteção de dados pessoais revitaliza-se, assim, como demanda de legitimidade procedimental na circulação de dados, como exigência de transparência, de necessidade e de proporcionalidade das medidas adotadas para coleta e tratamento dos dados.

Trata-se do início de uma mudança qualitativa que influenciou a legislação de vários países. É nesse contexto que se desenvolvem, quase simultaneamente, o Regulamento Geral de Proteção de Dados (RGPD) na Europa, e a Lei Geral de Proteção de Dados (LGPD) no Brasil. Existem vários pontos de contato entre as duas legislações. Nota-se, nos dois regimes de proteção de dados, a tentativa de integração de controles individuais e institucionais. Da mesma forma, é inegável o protagonismo atribuído às autoridades administrativas independentes, ainda que, no caso brasileiro, a Autoridade Nacional de Proteção de Dados (ANPD) tenha sido constituída recentemente após vários obstáculos à sua implementação, entre os quais, a omissão institucional.

O sucesso instrumental de alguns modelos, como o utilizado na Coreia do Sul, contribui para a criação de uma falsa ideia, qual seja, a de que o combate à pandemia passa necessariamente pelo aumento da vigilância e pela coleta indiscriminada de dados pessoais. A utilização de dados pessoais para o combate à pandemia não representa, contudo, uma panaceia. Deve sempre ser vista como uma medida extrema, que somente pode ser utilizada quando baseada em garantias jurídicas e desde que associada a outras medidas sanitárias amparadas cientificamente.

A compreensão crítica de riscos na utilização de dados pessoais demanda uma análise que combine a um só tempo individualização de tecnologias empregadas - o que se busca fazer nos itens seguintes (2 e 3) -, e foco na alocação desigual desses riscos entre pessoas individual e coletivamente consideradas (item 4), uma análise, portanto, sensível às distintas camadas de vulnerabilidade acirradas com a pandemia e com o seu combate.

\section{CARTOGRAFIA COM DADOS ANONIMIZADOS E PRIVACYWASHING}

Em relação à pandemia, observam-se frequentemente iniciativas voltadas para utilização de dados na construção de mapas epidemiológicos com o objetivo de acompanhar a disseminação do vírus. Em 1854, por exemplo, o médico inglês John Snow cartografou os casos de cólera em Londres. Essa linguagem, que combina elementos gráficos e textuais, ganhou destaque nos estudos sanitários dos séculos $X X$ e XXI?.

No Brasil, destacaram-se, inicialmente, duas iniciativas implementadas no enfrentamento à pandemia: Sistema de Monitoramento Inteligente (SIMI-SP) e Índice

7 OLIVEIRA, I. J. de. A linguagem dos mapas: utilizando a cartografia para comunicar. Temporis(ação) (UEG), Cidade de

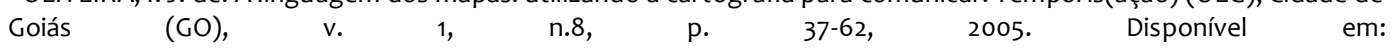
https://files.cercomp.ufg.br/weby/up/215/o/OLIVEIRA_Ivanilton_Jose_linguagem_dos_mapas.pdf Acesso em 20 jul 2020. 
de Isolamento Social (SII). O SIMI-SP ${ }^{8}$ envolve a coleta de dados de posicionamento de telefones celulares a partir da triangulação de antenas. Os dados coletados são agregados e anonimizados, sendo utilizados em mapas que podem indicar a movimentação da população e possíveis aglomerações. A Lei Geral de Telecomunicações (Lei $n^{\circ}$ 9.471/97) autoriza que as companhias telefônicas utilizem dados de forma agregada e anonimizada e, inclusive, autoriza o compartilhamento com terceiros ${ }^{9}$.

Mesmo com a utilização apenas de dados anonimizados e agregados, existem riscos que não podem ser negligenciados. O parecer do WP29 apontou que nenhuma das técnicas de anonimização está livre de falhas. ${ }^{10}$ Existem três riscos que devem ser considerados no processo de anonimização: (i) identificação - possibilidade de isolar alguns ou todos os registros que identifiquem uma pessoa num conjunto de dados; (ii) possibilidade de ligação - capacidade de ligar pelo menos dois registros sobre a mesma pessoa; e (iii) inferência - possibilidade de deduzir, com uma probabilidade significativa, o valor de um atributo a partir dos valores de um conjunto de outros atributos.

Diante disso, verifica-se que a narrativa da anonimização é problemática porque, por vezes, os aplicativos e serviços que coletam dados pessoais se limitam a informar que os dados serão anonimizados, porém, não há qualquer preocupação em esclarecer qual técnica de anonimização será utilizada e quais são os riscos técnicos, jurídicos e éticos envolvidos. O uso retórico da anonimização, juntamente com termos de uso e políticas de privacidade que se limitam a citar dispositivos da LGPD ou apenas indicam que os dados são anonimizados podem introduzir a prática de privacywashing, isto é, o falso marketing social de empresas que desejam construir uma reputação institucional marcada pela proteção dos dados do usuário, mas que, em concreto, não implementam medidas de segurança e procedimentos que efetivamente garantam esta proteção.

Várias técnicas específicas já foram propostas para anonimizar dados de trajetória de localização, a partir dos modelos k-anonimato, I-diversidade e t-proximidade ${ }^{11}$, mas de efetividade questionada por diversas pesquisas. ${ }^{12}$

\footnotetext{
8 O Governo do Estado de São Paulo apresenta o Sistema de Monitoramento Inteligente em: GOVERNO DE SÃO PAULO. Plano São Paulo. Disponível em: https://www.saopaulo.sp.gov.br/planosp/simi/ Acesso em 15 jun 2020.

${ }^{9}$ Art. 72. Apenas na execução de sua atividade, a prestadora poderá valer-se de informações relativas à utilização individual do serviço pelo usuário.

$\S 2^{\circ}$ A prestadora poderá divulgar a terceiros informações agregadas sobre o uso de seus serviços, desde que elas não permitam a identificação, direta ou indireta, do usuário, ou a violação de sua intimidade.

${ }^{10} \mathrm{O}$ Governo do Estado de São Paulo apresenta o Sistema de Monitoramento Inteligente em: GOVERNO DE SÃO PAULO. Plano São Paulo. Disponível em: https://www.saopaulo.sp.gov.br/planosp/simi/ Acesso em 15 jun 2020.

"Wang et al apontam que Osman et al. propuseram uma técnica para proteger a privacidade, alterando os pontos de trajetória no espaço próximos um do outro no tempo, Marco et al. propuseram um algoritmo denominado GLOVE para garantir o k-anonimato de trajetórias por meio de generalização espaço-temporal especializada, Gergely et al. estudaram um esquema de anonimização para liberar dados de densidade espaço-temporal com base na privacidade diferencial e Andres et al. introduziram a geo-indistinguibilidade a partir de critérios de privacidade diferencial para garantir que a localização exata do usuário seja desconhecida, mantendo a utilidade suficiente para determinado serviço desejado. WANG, Huandong; GAO, Chen; LI, Yong; WANG, Gang; JIN, Depeng; SUN, Jingbo. De-anonymization of Mobility Trajectories: Dissecting the Gaps between Theory and Practice. Proceedings 2018 Network and Distributed System Security Symposium. 18-21 de fevereiro de 2018, San Diego, CA, USA. DOI: http://dx.doi.org/10.14722/ndss.2018.23211

${ }^{12}$ Montjoye et al concluíram, a partir do estudo de dados de um milhão e meio de indivíduos durante quinze meses, que os traços de mobilidade humana são altamente exclusivos. Os pesquisadores apontam que em um conjunto de dados em que a localização de um indivíduo é especificada a cada hora e com uma resolução espacial igual à fornecida por antenas, quatro pontos de "espaço-tempo" são suficientes para identificar $95 \%$ dos indivíduos. DE MONTJOYE, Y; HIDALGO, C; VERLEYSEN, M.. et al. Unique in the Crowd: The privacy bounds of human mobility. Scientific Reports v. 3,
} 
Recentemente, foi divulgada uma reidentificação realizada a partir dos dados de geolocalização do serviço Smart Steps, comercializado pela empresa Telefônica S.A. A jornalista Tatiana Dias acessou uma planilha vendida em 2017 ao governo do Espírito Santo, que buscava compreender o fluxo de turistas dentro no estado. A planilha com as movimentações foi disponibilizada no site da Secretaria de Turismo, a jornalista procurou por eventos em cidades pequenas e filtrou as categorias de busca até atingir públicos específicos. A partir de informações públicas obtidas em redes sociais, foi possível identificar pessoas que eram clientes da empresa telefônica e que confirmaram ter visitado o local naquela ocasião e possuir as características descritas pelo produto, como a faixa etária. ${ }^{13}$

Esse caso ajuda a comprovar o "Mito do Superusuário". Trata-se da ideia de que poucas pessoas seriam capazes de combinar os bancos de dados, de que o "adversário" seria uma espécie rara de usuário, com conhecimentos avançados para realizar reidentificações. Contudo, os estudos e a ocorrência de situações como a apresentada têm demonstrado que há certa facilidade na reidentificação. Embora o usuário médio de computador não possa realizar uma junção interna, a maioria das pessoas que fez um curso em gerenciamento de banco de dados ou trabalhou em TI provavelmente é capaz de replicar as técnicas de reidentificação por meio de softwares acessíveis ${ }^{14}$.

Conforme foi demonstrado, as iniciativas que monitoram a pandemia de coronavírus a partir da criação de mapas cartográficos baseados em dados agregados e anonimizados, em princípio, são menos invasivas no que diz respeito à privacidade individual, uma vez que os dados são considerados como um todo e não de forma individualizada. Contudo, além dos riscos de reidentificação, também há uma preocupação com a privacidade coletiva. Por isso, a atenção jurídica, filosófica e analítica dada ao indivíduo precisa ser ajustada e, possivelmente, ampliada para passar a abranger a privacidade de grupos. Embora as tecnologias digitais já tenham evoluído para poder identificar pessoas com elevado grau de precisão, nem sempre isso será relevante porque, por vezes, é mais valioso - comercialmente, politicamente, socialmente - não se concentrar em um único indivíduo, mas em vários, isto é, focar em grupos ${ }^{15}$.

A atual concepção de privacidade centrada na identificabilidade individual se torna problemática quando o objetivo de um adversário não é identificar indivíduos, mas sim um grupo de interesse, como uma minoria étnica ou uma rede política. A capacidade de encontrar grupos por meio de rastros digitais anônimos oferece oportunidades a

n. 1376 (2013). DOI https://doi.org/10.1038/srep01376. Na mesma direção, os cientistas da computação Narayanan e Felten demonstraram que não existe um método efetivo para anonimizar dados de localização. NARAYANAN, Arvind; FELTEN, Edward W. No Silver Bullet: De-identification Still Doesn't Work. 9 de julho de 2014. Disponível em: http://randomwalker.info/publications/no-silver-bullet-de-identification.pdf Acesso em 20 jul 2020.

13 DIAS, Tatiana. Vigiar e lucrar: nós identificamos dois clientes dos dados de localização “anônimos" vendidos pela Vivo. The Intercept Brasil. 13 de abril de 2020. Disponível em: https:/theintercept.com/2020/04/13/vivo-venda-localizacaoanonima/ Acesso em 20 jul 2020.

${ }^{14} \mathrm{OHM}$, Paul. Broken promises of privacy: responding to the surprising failure of anonymization. UCLA Law Review, n. 57, p. 1731, 2010.

15 TAYLOR, Linnet; FLORIDI, Luciano; SLOOT, Bart van Der. Introduction: a new perspective on privacy. In: TAYLOR, Linnet; FLORIDI, Luciano; SLOOT, Bart vanDer (ed.). Group Privacy: new challenges of data technologies. New Challenges of Data Technologies. Cham, Suiça: Springer International Publishing, 2017. p. 1-12. (Philosophical Studies Series). 
poderes opressivos ou autoritários para prejudicar o grupo ou suprimir suas atividades ${ }^{16}$.

O desafio é o anonimato do grupo como um todo. Além da possibilidade de reidentificar indivíduos em um conjunto de dados, também há o problema de visibilidade do grupo. Os riscos do uso indevido de dados no contexto de traços móveis decorrem principalmente de assimetrias de poder e quando o tratamento ocorre sob condições de maximização de dados e regulamentação mínima há um risco de potencializar a assimetria informacional. A anonimização não é uma resposta suficiente para os desafios complexos do uso de dados de localização de populações potencialmente vulneráveis em áreas de pobreza, instabilidade política ou crise, nas quais os riscos decorrentes de violações da privacidade podem ser coletivos ou individuais e podem envolver perigo físico, em vez de marketing indesejado e demais problemas enfrentados por usuários em países de alta renda ${ }^{17}$.

No Brasil, na cidade de Miranda, no Mato Grosso do Sul, foram registrados uma série de ataques e ameaças contra a população indígena, que estava sendo acusada pela disseminação do vírus. Foi relatado que uma série de áudios que traziam acusações e incitavam violência e ódio circularam na cidade ${ }^{18}$. A Prefeitura de Miranda divulgou um boletim epidemiológico acerca do avanço da doença segregando os dados de indígenas e não-indígenas e noticiou que "o primeiro caso foi confirmado no último dia 16 de julho na comunidade indígena da Aldeia Moreira"19.

A plataforma "Covid-19 e os Povos Indígenas" destaca que povos indígenas são mais vulneráveis a epidemias em função de condições sociais, econômicas e de saúde inferiore ${ }^{20}$. $O$ "Indicador de vulnerabilidade das Terras Indígenas em relação a COVID19", organizado pelo Centro de Sensoriamento Remoto (CSR-UFMG) e o Instituto Socioambiental, apresenta um índice de vulnerabilidade, no qual os valores situam entre 0 a 1, nesse sentido, quanto mais próximo de 1 , maior o grau de vulnerabilidade da Terra Indígena. A Nota Técnica divulgada em 26/07/2020 ${ }^{21}$ demonstra que a mediana do índice de vulnerabilidade é de 0,487, sendo que, em $75 \%$ das Terras Indígenas (terceiro quartil), o índice de vulnerabilidade é de 0,494.

No Chile, um jornal divulgou o banco de dados georreferenciados do Ministério da Saúde na forma de mapas, que permitem a visualização específica dos casos confirmados de coronavírus em ruas e bairros ${ }^{22}$. De acordo com o jornal, cada ponto

\footnotetext{
${ }^{16}$ TAYLOR, Linnet. Safety in Numbers? Group Privacy and Big Data Analytics in the Developing World. In: TAYLOR, Linnet; FLORIDI, Luciano; SLOOT, Bart van Der (ed.). Group Privacy: new challenges of data technologies. New Challenges of Data Technologies. Cham, Suíça: Springer International Publishing, 2017. p. 13-36. (Philosophical Studies Series).
}

17 TAYLOR, Linnet. No place to hide? The ethics and analytics of tracking mobility using African mobile phone data. Environment and Planning D: Society and Space. 34. 2015. DOI: 10.1177/0263775815608851.

${ }^{18}$ MARQUES, Humberto. Ameaças contra indígenas por 'levarem coronavírus' geram tensão em aldeias de MS. Jornal Midiamax. 24 de julho de 2020. Disponível em: https://www.midiamax.com.br/cotidiano/2020/gravacoes-comacusacoes-e-ameacas-contra-indigenas-por-levar-coronavirus-a-cidade-de-ms-geram-tensao-em-aldeias. Acesso em: $30 / 07 / 2020$

19 PREFEITURA MUNICIPAL DE MIRANDA. Miranda contabiliza seis casos positivos para a Covid-19. 21 de julho de 2020. Disponível em: https://miranda.ms.gov.br/miranda-contabiliza-seis-casos-positivos-para-covid-19/. Acesso em: $30 / 07 / 2020$

${ }^{20}$ A plataforma “Covid-19 e os Povos Indígenas” está disponível em: https://covid19.socioambiental.org/

${ }^{21}$ OLIVEIRA, Ubirajara. Et al. Modelagem da vulnerabilidade dos povos indígenas no Brasil ao covid-19. 2020. Disponível em: https://drive.google.com/file/d/1H596_oDmOGf4mOTziHGIrbYM17PdycVj/view. Acesso em: 30/07/2020.

22 HERRERO, Victor A. Exclusivo: Estos son los mapas de contagio de Covid-19 que Mañalich mantiene en secreto. Interferencia. 11 de maio de 2020. Disponível em: https://interferencia.cl/articulos/exclusivo-estos-son-los-mapas-decontagio-de-covid-19-que-manalich-mantiene-en-secreto. Acesso em: 30/07/2020. 
que indica um caso testado positivo para a doença foi movido entre 50 e 100 metros de seu local de origem. Apesar da adição de ruído, é possível visualizar blocos, prédios e casas específicas nas quais há casos confirmados. A divulgação dos mapas foi criticada por possibilitar a identificação dos indivíduos a partir da associação de seus endereços com os pontos apresentados nos mapas ${ }^{23}$. Além disso, a publicação da localização dos casos da doença representa enorme potencial discriminatório. Em Vallenar, um grupo atacou uma casa habitada por três pessoas contaminadas pelo vírus e, em Quilicura, houve uma reação violenta contra haitianos que também haviam testado positivo para o vírus ${ }^{24}$.

Como a cartografia possibilita a visualização do cumprimento das políticas de isolamento social ou do número de casos confirmados em determinados locais, é possível realizar inferências que associam a disseminação da doença, o local e o grupo que habita ou frequenta este local. No Rio de Janeiro, um arquiteto criou a plataforma "Covid por CEP" 25 , alimentada por dados divulgados pela Prefeitura do Rio de Janeiro, na qual é possível verificar quantos casos confirmados existem em determinado CEP. Nesse caso, seria possível, por exemplo, associar um CEP com alta concentração de determinado grupo étnico ao avanço da doença, o mesmo poderia ocorrer com a identificação de locais de práticas religiosas minoritárias ou locais frequentados pela população LGBTQIA+.

Nesse sentido, Floridi ${ }^{26}$ aponta que os riscos envolvidos na abertura de dados pessoais anonimizados para uso público, nos casos em que grupos de pessoas ainda podem ser facilmente identificados e direcionados, estão sendo subestimados. No âmbito da União Europeia, o European Data Protection Board (EDPB) ${ }^{27}$ destacou que, quando se trata de usar dados de localização no contexto da pandemia de COVID-19, deve ser dada preferência ao processamento de dados anonimizados. Contudo, o EDPB reconhece que as técnicas de anonimização e a ciência da reidentificação são campos ativos de pesquisa, por isso, os agentes de tratamento que optam por implementar soluções de anonimização precisam monitorar os desenvolvimentos recentes desta área, principalmente quando há utilização de dados de localização, que são notoriamente mais difíceis de serem anonimizados porque o deslocamento de determinado indivíduo é único. Nesse sentido, o EDPB entende que, para alcançar a anonimização, os dados de localização devem ser processados como um todo, sem individualizar rotas de deslocamento de pessoas específicas. Além disso, a transparência em relação à metodologia de anonimização é altamente incentivada, visto que existem diversas técnicas e desenvolvimentos constantes neste campo.

\footnotetext{
23 DATOS PROTEGIDOS. ¿Por qué lo publicado por Interferencia.cl implica una grave transgresión a la privacidad y al derecho a la protección de los datos personales?. 14 de maio de 2020. Disponível em: https://datosprotegidos.org/porque-lo-publicado-por-interferencia-cl-implica-una-grave-transgresion-a-la-privacidad-y-al-derecho-a-la-proteccion-delos-datos-personales/. Acesso em: 30/07/2020.

${ }^{24}$ MORALES, Felipe Vargas. Protegerlos de hostigamientos o tener información para ayudarlos: El debate sobre el acceso a datos de los pacientes. Emol.com. 23 de abril de 2020. Disponível em: https://www.emol.com/noticias/Nacional/2020/04/23/984003/Gobierno-Datos-Alcaldes-Coronavirus.html. Acesso em: 30/07/2020.

${ }^{25}$ A plataforma "Covid por CEP" pode ser acessada em: https://covidporcep.rio.br/

${ }^{26}$ FLORIDI, Luciano. Group Privacy: a defence and an interpretation. In: TAYLOR, Linnet et al (ed.). Group Privacy: new challenges of data technologies. [S.I]: Springer International Publishing, 2017. Cap. 5. p. 83-100.

27 EUROPEAN DATA PROTECTION BOARD. Guidelines 04/2020 on the use of location data and contact tracing tools in the contexto of the COVID-19 outbreak. Bruxelas: [s.n.], 2020. Disponível em: https://edpb.europa.eu/our-worktools/our-documents/usmernenia/guidelines-042020-use-location-data-and-contact-tracing_en. Acesso em: 15 de julho de 2020.
} 
Sendo assim, observa-se que as técnicas de anonimização podem ser utilizadas como instrumentos retóricos responsáveis por (i) construir a reputação institucional de preocupação com a privacidade do usuário, enquanto não há qualquer ação concreta para garantia de segurança dos dados; (ii) neutralizar conflitos, atenuando o impacto de potenciais violações na utilização de dados pessoais; (iii) afastar a aplicação do regime de proteção de dados pessoais, uma vez que dados anonimizados estão fora do escopo de proteção legal. Nesse cenário, a ausência de agentes externos que atuem na fiscalização do uso de técnicas de anonimização, evidenciando as possíveis falhas e riscos envolvidos, favorece a construção de um cenário de insegurança jurídica e abre espaço para a prática de privacywashing.

\section{RASTREAMENTO DE CONTATOS (CONTACT TRACING)}

Ao lado das técnicas supostamente mais inofensivas de coleta de dados, o combate à pandemia tem suscitado a utilização de medidas de caráter incontroversamente mais invasivo, como é o caso do rastreamento de contato (contact tracing).

A utilização de contact tracing não surgiu, porém, com a pandemia da COVID-19, tampouco está necessariamente relacionada ao uso de tecnologias, pois pode ser feita manualmente a partir de entrevistas presenciais ou por ligação telefônica ${ }^{28}$.

O rastreamento de contatos é intervenção clássica de saúde pública, usada comumente e de modo bem sucedido no controle de epidemias diversas, a exemplo do caso ebola. Tradicionalmente envolve pessoal de saúde treinado entrevistando determinado indivíduo ("index case", o primeiro caso de um grupo de casos relacionados de uma específica doença transmissível), com a finalidade de identificar os movimentos dessa pessoa no período em que esteve infectada e de outras pessoas potencialmente expostas. Um profissional de saúde realiza contato direto e privado com qualquer pessoa em risco, incentivando-a a se testar e a tomar medidas de prevenção da transmissão do vírus ${ }^{29}$.

Os dados obtidos são ou deveriam ser protegidos por regras rigorosas de confidencialidade, mas há problemas de vazamentos e de discriminação no setor de saúde amplamente documentados. Por exemplo, em relação a pessoas vivendo com HIV, mesmo após mais de 30 anos da epidemia da doença, sentem-se os impactos da forma desastrosa como os dados sobre a doença vieram a público, com foco em grupos de pessoas, e não em práticas consideradas arriscadas, criando-se estigma de trabalhosa superação ${ }^{30}$.

A atual crise global de saúde gerou uma proliferação de iniciativas de rastreamento digital de contatos, que usa dispositivos transportados por pessoas, como, por exemplo, um smartphone, para medir a proximidade entre elas ${ }^{31}$.

\footnotetext{
${ }^{28}$ Leong, Kan-Ion \& Si, Yain Whar \& Biuk-Aghai, Robert \& Fong, Simon. (2009). Contact Tracing in Healthcare Digital Ecosystems for Infectious Disease Control and Quarantine Management. 2009 3rd IEEE International Conference on Digital Ecosystems and Technologies, DEST '09. 306 - 311. 10.1109/DEST.2009.5276730.

29 DAVIS, Sara L. M. Contact Tracing Apps: Extra Risks for Women and Marginalized Groups. In.: Health and Human Rights Journal. Abril de 2020. Disponível em: https://www.hhrjournal.org/2020/04/contact-tracing-apps-extra-risks-forwomen-and-marginalized-groups/ Acesso em 15 jun 2020

$3^{\circ}$ DAVIS, Sara L. M. Contact Tracing Apps: Extra Risks for Women and Marginalized Groups. In.: Health and Human Rights Journal. Abril de 2020. Disponível em: https://www.hhrjournal.org/2020/04/contact-tracing-apps-extra-risks-forwomen-and-marginalized-groups/ Acesso em 15 jun 2020

${ }^{31}$ Como parte de suas respostas ao surto de COVID-19, China, Coréia do Sul e Cingapura estão usando aplicativos que empregam várias combinações de GPS, Bluetooth (que troca sinais entre dois telefones celulares dentro de uma certa
} 
Os dados coletados por aplicativos de contact tracing são analisados por um algoritmo de pontuação de risco de acordo com determinados parâmetros (como a distância da aproximação e o número de contatos que o indivíduo teve com supostos infectados) e, desse modo, determina-se se o usuário deve ser alertado sobre um possível contato e quais medidas ele deve tomar. Observa-se que o funcionamento do rastreamento depende da identificação de que determinada pessoa foi contaminada. ${ }^{32}$

A infecção pode ser relatada a um aplicativo de rastreamento de contato digital a partir de diferentes formas ${ }^{33}$ : o indivíduo pode declarar estar contaminado e enviar a declaração de um médico ou de teste com resultado positivo para o vírus; profissionais da saúde poderiam notificar o serviço de rastreamento de contato digital que seu paciente está infectado; ou as autoridades de sanitárias poderiam fazer upload de uma lista de pacientes infectados.

Apple e Google anunciaram uma parceria para desenvolvimento de uma Application Programming Interface - API (Interface de Programação de Aplicações, são conjuntos e funções utilizadas no desenvolvimento de programas e aplicativos) que usa Bluetooth Low Energy (BLE). A API pode ser incorporada em aplicações de rastreamento, mas isoladamente não possui utilidade. $O$ indivíduo que utiliza $O$ aplicativo e consente em participar do rastreamento passa a ter um código de identificação e uma chave de rastreamento únicos. O código de identificação é uma sequência de números aleatórios que muda a cada período de 10 a 20 minutos, sendo transmitido pelo celular de uma pessoa, por meio do Bluetooth, e recebido por outros aparelhos que estejam próximos.

Apesar de utilizar o protocolo Bluetooth, os aplicativos também podem coletar dados de localização ou sobre como o usuário interage com o aplicativo. Essa funcionalidade está relacionada ao design do aplicativo e ocorre independentemente do protocolo utilizado. $\mathrm{O}$ aplicativo pode ser projetado para usar modelos descentralizados ou centralizados. No caso de modelos de estrutura centralizada os dados coletados são armazenados e analisados em um local central. Em modelos descentralizados, a verificação de contato é feita nos próprios celulares, por exemplo, os smartphones fazem o download regular da lista de IDs relatados como infectados e notificam o usuário se necessário 34 .

O DP-3T (Decentralized Privacy-Preserving Proximity Tracing) é um rastreamento de proximidade descentralizado que busca preservar a privacidade de usuários. Trata-se de um protocolo de código aberto para rastreamento baseado em Bluetooth, no qual

distância) e sinais wifi para localizar indivíduos e alertar aqueles que podem ter estado em contato com casos confirmados de COVID-19. DAVIS, Sara L. M. Contact Tracing Apps: Extra Risks for Women and Marginalized Groups. In.: Health and Human Rights Journal. Abril de 2020. Disponível em: https://www.hhrjournal.org/2020/04/contact-tracingapps-extra-risks-for-women-and-marginalized-groups/

32 EUROPEAN DATA PROTECTION BOARD. Guidelines 04/2020 on the use of location data and contact tracing tools in the contexto of the COVID-19 outbreak. Bruxelas: [s.n.], 2020. Disponível em: https://edpb.europa.eu/our-worktools/our-documents/usmernenia/guidelines-042020-use-location-data-and-contact-tracing_en. Acesso em 30 de maio de 2020.

33 O funcionamento técnico e as limitações de cada tecnologia são explorados em HART, V. et al. Outpacing the Virus: Digital Response to Containing the Spread of COVID-19 while Mitigating Privacy Risks. Edmond J. Safra Center for Ethics. 2020. Disponível em: https://ethics.harvard.edu/outpacing-virus e KIND, Carly. Exit through the App Store?. Ada Lovelace Institute. 2020. Disponível em:https://www.adalovelaceinstitute.org/our-work/covid-19/covid-19-exit-throughthe-app-store/ Acesso em 15 jun 2020.

34 HIGA, Paulo. Como funciona a tecnologia feita por Apple e Google para monitorar COVID-19. Tecnoblog. 24 de abril de 2020. Disponível em: https://tecnoblog.net/335748/como-funciona-a-tecnologia-feita-por-apple-e-google-paramonitorar-covid-19/. Acesso em: 30/07/2020 
os registros de contato de um telefone individual são armazenados apenas localmente, sendo menos vulnerável à vigilância em massa ou à violação de dados.

Contudo, algumas limitações técnicas já foram identificadas no funcionamento dos serviços de rastreamento digital. Há certa imprecisão na detecção do contato, uma vez que é necessário utilizar parâmetros objetivos como distância e tempo para verificar quando ocorre um incidente de contato, mas não é possível controlar variáveis como ventilação e contato com superfícies e objetos contaminados.

Também verifica-se imprecisão na detecção da distância. As iniciativas de monitoramento da pandemia se concentram em quatro mecanismos técnicos para detectar a distância - GPS, sinais de rede móvel, sinais WiFi ou Bluetooth - e cada um deles possui suas limitações. O GPS funciona melhor em ambientes externos, por isso, terá mais imprecisão ao determinar o contato entre pessoas dentro de edifícios ou transporte subterrâneo. A maior vantagem dos registros de localização móvel é que boa parte dos smartphones já está gravando dados de localização (por exemplo, há a linha do tempo do Google Maps e o armazenamento local criptografado em dispositivos iOS). Desse modo, um usuário pode instalar um aplicativo de combate à pandemia hoje e receber avisos sobre exposições que podem ter acontecido na semana anterior. Essa funcionalidade é importante porque permite que aqueles que testaram positivo para o vírus instalem um aplicativo após esse diagnóstico e ainda que pessoas que estiveram em contato possam ser notificadas. ${ }^{35}$

Além das limitações técnicas, existem limitações éticas e sociais que não podem ser ignoradas. O rastreamento de contato digital é suscetível a fraudes e a abusos, a exemplo de pessoas que usam vários dispositivos e reportam relatórios falsos de infecção.

As tecnologias citadas só serão úteis se houver adesão social voluntária. A obrigatoriedade do uso de aplicativos de monitoramento poderia, inclusive, ter o efeito oposto, minando a confiança dos cidadãos. Morley, Cowls, Taddeo e Floridi apontam que, mesmo diante de uma crise global, é necessário considerar riscos éticos e implementar medidas adequadas para impedir que dados coletados sob a justificativa de contenção da pandemia sejam utilizados de forma potencialmente antiética, impactando a privacidade dos cidadãos de modo irreversível. ${ }^{36}$

Após as manifestações antirracistas e antifascistas ocorridas em diversas cidades estadunidenses, especialmente após o brutal assassinato de George Floyd, em 25 de maio do presente ano, intensifica-se o debate sobre como a liberdade de expressão, direito de reunião, entre outros, são impactados pelo rastreamento digital de contatos realizado no contexto de pandemia. Isso porque, sob a alegação de combate à violência de parte das manifestações "black lives matter", algumas cidades, entre as quais Minneapolis, valeram-se da tecnologia, cujo uso foi justificado com a pandemia, para identificar e perfilizar manifestantes ${ }^{37}$.

\footnotetext{
${ }^{35}$ As informações sobre esta funcionalidade no uso de GPS estão disponíveis no White paper "Outpacing the Virus: Digital Response to Containing the Spread of COVID-19 while Mitigating Privacy Risks" publicado pelo Edmond J. Safra Center for Ethics - Harvard em 3 de abril de 2020. Disponível em: https://ethics.harvard.edu/outpacing-virus.

${ }^{36}$ MORLEY, Jessica; COWLS, Josh; TADDEO, Mariarosaria; FLORIDI, Luciano, Ethical Guidelines for SARS-CoV-2 Digital Tracking and Tracing Systems (2020). Disponível em: https://ssrn.com/abstract=3582550 ou http://dx.doi.org/10.2139/ssrn.3582550. Acesso em 22/05/2020

37 COLLINS, Lois. Will protests change how contact tracing for COVID-19 works? Finding those who were potentially exposed to the coronavirus is key to stopping the spread, according to experts. Deseret News. Disponível em: https://www.deseret.com/indepth/2020/6/19/21292151/protests-salt-lake-county-johns-hopkins-university-health-covid19-contact-tracing Acesso em 15 jun 2020
} 
A perfilização, por sua vez, ao se relacionar mais diretamente com grupos sociais do que com pessoas individualmente consideradas, tensiona ainda mais a matriz individualista, que tradicionalmente acompanha o debate da proteção de dados pessoais ${ }^{38}$.

Outro ponto importante, sobre uso de rastreamento digital de contatos no combate à COVID-19, é que as pessoas que são mais vulneráveis ao vírus podem não ter acesso à Internet, possuir um smartphone ou ter a alfabetização digital necessária para utilizar estes aplicativos ${ }^{39}$.

Morley, Cowlsi, Taddeo e Floridi apontam que os sistemas de rastreamento digital para enfrentamento à pandemia de Covid-19 não podem ser implantados havendo lacunas de orientação, pois podem limitar rigorosamente os direitos e liberdades fundamentais, gerando pânico social, exposição, erosão da confiança no governo e nos serviços públicos de saúde ou desigualdade. ${ }^{40}$

Rob Kitchin aponta que, atualmente, as tecnologias utilizadas no rastreamento digital de contatos não conseguem determinar contatos próximos significativos de forma confiável, correndo o risco de sobrecarregar o sistema com falsos positivos. ${ }^{41} \mathrm{O}$ autor entende que as iniciativas de rastreamento de contatos mediadas por tecnologia só serão eficazes na prática se: (i) houver um programa de teste em massa, com certificação que confirme que uma pessoa está com o vírus; (ii) houver baixo número de casos; (iii) $60 \%$ da população participar; e (iv) existir uma base legislativa sólida para a implantação destas soluções ${ }^{42}$.

Diante das deficiências e dificuldades apresentadas, não há dúvida de que o rastreamento de contato baseado em tecnologia pode apenas complementar, e não substituir, os métodos tradicionais.

\footnotetext{
38 ZANATTA, RAFAel A. Perfilização, Discriminação e Direitos: do Código de Defesa do Consumidor à Lei Geral de Proteção de Dados Pessoais. https://www.researchgate.net/publication/331287708_Perfilizacao_Discriminacao_e_Direitos_do_Codigo_de_Defesa_ do_Consumidor_a_Lei_Geral_de_Protecao_de_Dados_Pessoais Acesso em 15 jun 2020. No mesmo sentido: O'NEIL, Cathy. Weapons of math destruction: How big data increases inequality and threatens democracy. Broadway Books, 2016.

${ }^{39}$ A pesquisa TIC Domicílios 2019 constatou que a Internet está presente em $71 \%$ dos domicílios brasileiros, porém, mais de 20 milhões de domicílios não possuem conexão à Internet, realidade que afeta especialmente domicílios da região Nordeste (35\%) e famílias com renda de até 1 salário mínimo (45\%). A pesquisa mostrou ainda que $47 \%$ buscaram informações sobre saúde, com menor proporção entre idosos (39\%) e nas classes DE (31\%). CGI.br; NIC.br; Centro Regional de Estudos para o Desenvolvimento da Sociedade da Informação (Cetic.br). Pesquisa sobre o Uso das Tecnologias de Informação e Comunicação nos Domicílios Brasileiros - TIC Domićlios 2019. Disponível em: https://www.cetic.br/media/analises/tic_domicilios_2019_coletiva_imprensa.pdf . Acesso em 15 jun 2020.

${ }^{40}$ Sob a perspectiva dos autores, um sistema de rastreamento digital deveria satisfazer quatro princípios de alto nível (necessidade, proporcionalidade, solidez científica e prazo) e ainda a diversos fatores de habilitação adicionais mais concretos: voluntariedade; consentimento; uso de dados anônimos; possibilidade dos dados serem apagados; finalidade definida e limitada; uso para prevenção e não para monitoramento do comportamento do usuário; opensource; uso disponível e acessível para todos; planejamento claro posterior desativação do app. MORLEY, Jessica; COWLS, Josh; TADDEO, Mariarosaria; FLORIDI, Luciano, Ethical Guidelines for SARS-CoV-2 Digital Tracking and Tracing Systems (2020). Disponível em: https://ssrn.com/abstract=3582550 ou http://dx.doi.org/10.2139/ssrn.3582550. Acesso em $22 / 05 / 2020$

${ }^{41}$ KITCHIN, Rob. Civil liberties or public health, or civil liberties and public health? Using surveillance technologies to tackle the spread of COVID-19. Space And Polity, [s.I.], p. 1-20, 3 jun. 2020. Informa UK Limited. http://dx.doi.org/10.1080/13562576.2020.1770587._Acesso em 22/05/2020.

42 KITCHIN, Rob. Civil liberties or public health, or civil liberties and public health? Using surveillance technologies to tackle the spread of COVID-19. Space And Polity, [s.I.], p. 1-20, 3 jun. 2020. Informa UK Limited. http://dx.doi.org/10.1080/13562576.2020.1770587._Acesso em 22/05/2020.
} 


\section{TECNOLOGIA, PANDEMIA E VULNERABILIDADE}

Como já sinalizado neste trabalho, o amplo alcance da COVID-19 abastece a lógica de equiparação dos impactos da pandemia. O risco constante de adoecimento, de morte, de morte de alguém próximo, colocado em alguma medida para toda a comunidade humana, reforça o sentido universal não apenas da finitude, mas também da precariedade da vida, a ideia de que a vida não está garantida a ninguém.

De acordo com Butler, a precariedade diz respeito ao viver socialmente, a uma dimensão inevitável, relacional, de dependência recíproca para que a vida seja mantida, retroativamente ao próprio nascimento. Do fato de uma criança poder ou não sobreviver é que deriva a necessidade de se cuidar para que ela viva. Nesse sentido, a possibilidade de "enlutamento", de a perda da vida assumir algum valor, é pressuposto de surgimento e manutenção da vida43. Por outro lado, a condição de "ser passível de luto" é condicionada pela adequação da vida às normas que a caracterizam como vida, como vida válida.

Segundo a autora, o "ser" está sempre entregue ao (s) outro (s), à modelagem social (normas), a forças articuladas social e politicamente, que lhe determinam subsistência e prosperidade. Nesse ponto é que Butler diferencia os conceitos de precariedade (precariousness) e de condição precária (precarity), justamente para sublinhar que a alocação diferencial da precariedade por essas forças, estruturas, acirra a condição precária de determinadas pessoas e grupos, isto é, a condição de uma vulnerabilidade politicamente induzida, "na qual certas populações sofrem com redes sociais e econômicas de apoio deficientes e ficam expostas de forma diferenciada às violações, à violência e à morte" 44 .

Se o contexto da pandemia deixa, de um lado, mais evidente a interdependência global para que se mantenham as estruturas viabilizadoras da vida; de outro, como alerta Butler, intensifica o processo de desigualdade radical entre seres humanos, repercutindo de forma mais crítica sobre populações já em situação de vulnerabilidade, considerando-se dissidências de gênero, de sexualidade, marcadores de raça, status de cidadania e nacionalidade ${ }^{45}$.

$\mathrm{Na}$ busca pelas melhores estratégias de combate à pandemia, de garantia da vida (válida, enlutável), há um rastro de violações especialmente desproporcionais a outras vidas.

$\mathrm{Na}$ China, entre as medidas de prevenção e contenção da COVID-19, incluindo testes, amostragem e quarentena compulsória, revelou-se um padrão altamente seletivo sem qualquer embasamento científico. As autoridades incumbidas dessas tarefas miraram em residentes africanos para testagem, chegando, em alguns casos, a emitir ordens de isolamento nas respectivas residências, acompanhadas de instalação de câmeras de vigilância ou alarmes próximos aos locais. Boa parte dessas pessoas já haviam testado negativo para o coronavírus, não apresentavam histórico recente de viagens ou de contato com pacientes diagnosticados com a COVID-19.

\footnotetext{
${ }^{43}$ BUTLER, Judith. Quadros de Guerra: quando a vida é passível de luto? Tradução de Sérgio Lamarão e Arnaldo Marques da Cunha. Rio de Janeiro: Civilização Brasileira, 2016, p. 33.

${ }^{44}$ BUTLER, Judith. Quadros de Guerra: quando a vida é passível de luto? Tradução de Sérgio Lamarão e Arnaldo Marques da Cunha. Rio de Janeiro: Civilização Brasileira, 2016, p. 46.

45 BUTLER, Judith. Judith Butler sobre a Covid-19: o capitalismo tem seus limites. Blog da Boitempo. Disponível em: https://blogdaboitempo.com.br/2020/03/20/judith-butler-sobre-o-covid-19-o-capitalismo-tem-seus-limites/. Acesso em 15 jun 2020.
} 
Foram relatados diversos casos de abuso de poder, de tratamento xenofóbico, racista e desumano de africanos na China, denunciados em carta aberta subscrita por mais de 300 grupos de direitos humanos à União Africana ${ }^{46}$.

Por sua vez, os governos do Peru e do Panamá pautaram-se por sistema binário de gênero para formulação de política pública restritiva de liberdade de locomoção voltada à contenção da COVID-19. Buscando diminuir a circulação de pessoas nas cidades, estabeleceram rodízio para saída de casa, a cada dia da semana, valendo-se do critério "mulheres x homens". Essa medida afetou sensivelmente pessoas dissidentes de gênero, especialmente pessoas trans e travestis, submetendo-as de modo ainda mais crítico a dispositivos disciplinares de vigilância, com grande número de detenção motivada por desobediência às regras de quarentena ${ }^{47}$.

Para tornar a circulação/aglomeração menos arriscada para a população em geral, adotou-se um caminho desproporcional, um caminho que, injustificadamente, reforçou o contexto de risco, de condição precária, de vulnerabilidade, das pessoas não binárias, confirmando-se a ausência de valor social de suas vidas, vidas não passíveis de luto. A medida ainda acaba por reproduzir e reforçar a divisão sexual do trabalho e de papéis sociais, o que também alimenta desigualdade entre homens e mulheres ${ }^{48}$.

O acirramento da condição precária de grupos vulneráveis não ocorre nesse contexto pandêmico apenas em decorrência de medidas deliberadamente discriminatórias ou de segregação. Pode vir como efeito colateral não calculado - mas ainda assim antecipável - de medidas restritivas mais abrangentes.

Contextos de emergências, de crises, tendem, historicamente, a exacerbar desigualdades, na medida em que ampliam desafios já vivenciados por grupos mais vulneráveis no acesso à saúde, à justiça, à educação, à moradia, a emprego e a outros serviços. Se a economia é afetada, mais ainda é o setor informal em que predominantemente se encontram pessoas mais vulneráveis, isso quando conseguem se inserir no mercado de trabalho. Violências domésticas já sofridas tendem a se ampliar com o isolamento e coabitação forçados, com o excesso de convivência. Se um sistema de saúde relativamente funcional já não é por vezes capaz de proporcionar a saúde integral de populações marginalizadas, beirando ao colapso a situação só tende a se agravar para esses grupos. ${ }^{49}$

Para além disso, o ambiente de medo e de ansiedade que se constrói com a pandemia revela-se propício para o fortalecimento de estigmas e de ódios que também historicamente tendem a culpabilizar grupos marginalizados pelas crises, reforçando discriminação e até violência, como se deu com a comunidade judaica com relação à

\footnotetext{
${ }^{46}$ Disponível em: https://www.aa.com.tr/en/africa/africa-calls-on-china-to-stop-covid-19-discrimination/1802375 Acesso em 15 jun 2020.

47 CORRÊA, Sonia. De volta ao de sempre: segregação por sexo/gênero como medida de contenção da Covid-19. Sexuality Policy Watch. Disponível em: https://sxpolitics.org/ptbr/de-volta-ao-de-sempre-segregacao-por-sexo-generocomo-medida-de-contencao-da-covid-19/10296. Acesso em 15 jun 2020.

${ }^{48}$ CORRÊA, Sonia. De volta ao de sempre: segregação por sexo/gênero como medida de contenção da Covid-19. Sexuality Policy Watch. Disponível em: https://sxpolitics.org/ptbr/de-volta-ao-de-sempre-segregacao-por-sexo-generocomo-medida-de-contencao-da-covid-19/10296. Acesso em 15 jun 2020.

49 OUTRIGHT ACTION INTERNATIONAL. Vulnerability Amplified: the impact of the

COVID-19 pandemic on LGBTIQ people. New York: OutRight Action International, 2020. Disponível em: <https://outrightinternational.org/sites/default/files/COVIDsReportDesign_FINAL_LR_o.pdf>. Acesso em 15 jun 2020.
} 


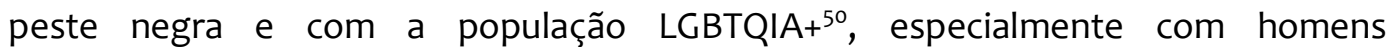
homossexuais e mulheres trans quanto à disseminação do vírus HIV51.

Por todos esses fatores, é particularmente emblemático o recente caso de vazamento de dados pessoais de pacientes com o coronavírus na Coreia do Sul. O país se destacou no combate à pandemia a partir da adoção combinada de diversas medidas, tais como rastreamento e monitoramento de infectados, controle de temperatura corporal, uso compulsório de máscaras e testagem ampla e maciça da população. Deparou-se, porém, com uma segunda onda de infecções, com grande concentração dos novos casos em um único bairro em Seul.

Um homem de 29 anos foi identificado como propagador do vírus. A partir da sua identificação, agências de notícias passaram a divulgar que esse homem teria visitado, em uma mesma noite, cinco estabelecimentos diferentes, frequentados pela população LGBTQIA+. O surto acabou sendo, então, vinculado nas redes sociais e em publicações locais a "clubes gays", ainda que os estabelecimentos implicados nem se descrevessem particularmente como voltados ao público LGBTQIA+. Mídias sul coreanas especificaram idade, região da contaminação, profissão e local de trabalho dos pacientes diagnosticados com o coronavírus ${ }^{52}$.

Uma forte reação contrária à população LGBTQIA+, culpabilizando-a pela propagação da COVID-19, ganhou espaço, com disseminação de mensagens de ódio, ataques homofóbicos, ameaças. Além da escalada da violência e de reforço de estigmas, prejudicou-se o contato de autoridades sanitárias com os milhares de frequentadores dos clubes, o que levou o governo a adotar outras medidas de rastreamento, via cartões de crédito, câmeras de segurança e registros de torre de sinal de telefone ${ }^{53}$.

Esse tipo de situação agrava ainda mais a condição precária, a vulnerabilidade politicamente induzida, da população LGBTQIA+, como sinalizam os relatos de pessoas que temem perder seus empregos se forem testadas e submetidas a isolamento compulsório; e a circunstância de que a testagem obrigatória de frequentadores dos clubes pode conduzir à exposição da sua orientação sexual contra a sua vontade ${ }^{54}$.

A capital da Índia, Nova Délhi, sediou também episódio de vazamento de dados. Redes sociais divulgaram amplamente uma lista com 10 nomes, de pessoas associadas ao movimento missionário islâmico Tablighi Jamaat, e dados pessoais como endereços, contatos telefônicos e respectivos resultados de testes para COVID-19, parte deles positivos $^{55}$.

\footnotetext{
${ }^{50} \mathrm{O}$ trabalho opta pelo termo LGBTQIA+ por permitir reconhecimento das identidades dissidentes de sexualidade e de gênero (lésbicas, gays, bissexuais, transgêneras, queer, interesexo e assexual) e, com o sufixo "+", indicar uma abertura epistêmica necessária, para que não seja sugerido caráter fixo ou estável dessa identidade coletiva, e para que se reduza a objetificação do grupo.

${ }^{51}$ OUTRIGHT ACTION INTERNATIONAL. Vulnerability Amplified: the impact of the

COVID-19 pandemic on LGBTIQ people. New York: OutRight Action International, 2020. Disponível em: <https://outrightinternational.org/sites/default/files/COVIDsReportDesign_FINAL_LR_o.pdf>. Acesso em 15 jun 2020.

52 Disponível em: https://www.forbes.com/sites/alexandrasternlicht/2020/05/12/with-new-covid-19-outbreak-linked-togay-man-homophobia-on-rise-in-south-korea/\#4dfge3354909 Acesso em 15 jun 2020.

53 Disponível em: https://edition.cnn.com/2020/05/12/asia/south-korea-club-outbreak-intl-hnk/index.html Acesso em 15 jun 2020.

${ }^{54}$ Disponível em: https://edition.cnn.com/2020/05/12/asia/south-korea-club-outbreak-intl-hnk/index.html Acesso em 15 jun 2020.

55 Disponível em: https://www.forbes.com/sites/alexandrasternlicht/2020/05/12/with-new-covid-19-outbreak-linked-togay-man-homophobia-on-rise-in-south-korea/\#4dfge3354909 Acesso em 15 jun 2020.
} 
Ambos os casos evidenciam a fragilidade de determinadas ferramentas de rastreamento, quanto a dados pessoais sensíveis ${ }^{56}$, como os relacionados à orientação sexual, a preferências religiosas, à liberdade de associação política, entre outros, que historicamente se revelam mais propícios a práticas discriminatórias.

Grupos historicamente submetidos a opressões e violências estão expostos a um risco maior de perseguição à medida que os dados sobre a transmissão do coronavírus circulam e são debatidos na esfera pública. Mesmo dados anonimizados, ao entrarem em domínio público, propiciam inferências, acertadas ou não, voltadas à culpabilização.

No site Coronamap da Coreia do Sul foram divulgados históricos de viagens de pacientes diagnosticados, anonimizados, identificando-os apenas por sexo e idade. Mensagens de texto são enviadas às pessoas avisando-as sobre contatos específicos e respectivos movimentos. Há relatos, mesmo nesse cenário de dados anonimizados, de pessoas que foram acusadas de infidelidade, trabalho sexual, fraude, e de "caça às bruxas" online para identificar pessoas "culpadas" pela propagação do vírus 57.

Tendo em vista também contexto de grande desigualdade de gênero e de violência contra mulheres em muitos países, essas acusações podem ampliar subalternização dos corpos femininos. Dados sobre condição de saúde e movimentação podem desencadear especulações sobre atividades das mulheres por parte de seus parceiros, de sua família, vizinhos, expondo-as ainda mais a violências e discriminação.

A corrida para se adotar o rastreamento digital de contatos, desacompanhada de políticas de enfrentamento do estigma em torno da epidemia e de proteção adequada dos direitos de grupos especialmente vulneráveis, além de aprofundar a condição precária dessas pessoas, coloca em risco o próprio objetivo de controle da epidemia, a partir de um possível paradoxo de dados em que a falta dos mesmos conduz a não alocação de recursos para a saúde, que reforça, por sua vez, a escassez de dados ${ }^{58}$.

\section{CONCLUSÃO}

O presente trabalho teve por objetivo contribuir para uma compreensão crítica de inovações e tecnologias de coletas de dados no combate da pandemia da COVID-19, problematizando seus impactos mais acirrados sobre grupos com vulnerabilidade politicamente induzida.

O referencial teórico de Butler revelou-se bastante oportuno para se evidenciar a alocação diferencial da precariedade da vida entre a comunidade humana, conforme haja adequação às normas sociais, e a condição precária - acirrada com a pandemia a que estão especialmente submetidas pessoas cujas vidas não são passíveis de luto, em razão de marcadores de raça, gênero, status de nacionalidade, de cidadania e dissidências de sexualidade.

\footnotetext{
${ }^{56}$ Sobre dados sensíveis, conferir: MULHOLLAND, Caitlin. Dados pessoais sensíveis e a tutela de direitos fundamentais: uma análise à luz da lei geral de proteção de dados (Lei 13.709/18). Revista de Direitos e Garantias Fundamentais, v. 19, p. 159-180, 2018.

57 DAVIS, Sara L. M. Contact Tracing Apps: Extra Risks for Women and Marginalized Groups. In.: Health and Human Rights Journal. Abril de 2020. Disponível em: https://www.hhrjournal.org/2020/04/contact-tracing-apps-extra-risks-forwomen-and-marginalized-groups/ Acesso em 15 jun 2020

${ }^{8}$ DAVIS, Sara L. M. Contact Tracing Apps: Extra Risks for Women and Marginalized Groups. In.: Health and Human Rights Journal. Abril de 2020. Disponível em: https://www.hhrjournal.org/2020/04/contact-tracing-apps-extra-risks-forwomen-and-marginalized-groups/ Acesso em 15 jun 2020
} 
Com o detalhamento de tecnologias empregadas no combate à pandemia, combinado a análise de casos concretos, demonstrou-se a falta de proporcionalidade de medidas que vêm sendo naturalizadas no enfrentamento da crise, especialmente quanto a direitos de grupos politicamente vulneráveis, ora invisibilizados, ora excessivamente expostos e visados.

$\mathrm{Na}$ busca pelas melhores e mais eficientes estratégias de combate à pandemia, de segurança e garantia da vida (válida, enlutável), há um rastro de violações que exacerbam ainda mais a condição precária de grupos historicamente discriminados e oprimidos, o que compromete a adequação dessas saídas. Impõe-se, assim, a construção de alternativas mais legítimas, isto é, mais sensíveis às distintas camadas de vulnerabilidade a que as pessoas, individual e coletivamente, estão submetidas.

\section{REFERÊNCIAS}

ARTICLE 29 DATA PROTECTION WORKING PARTY. Opinion 5/2014 on Anonymisation techniques. Bruxelas: [s. n.], 2014. Disponível em: http://ec.europa.eu/justice/article29/documentation/opinion-recommendation/files/2014/wp216_en.pdf. Acesso em: 30 maio 2020.

BIONI, B. R. Proteção de dados pessoais: a função e os limites do consentimento. Rio de Janeiro. Forense, 2019.

BUTLER, Judith. Judith Butler sobre a Covid-19: o capitalismo tem seus limites. Blog da Boitempo. 2020. Disponível em: https://blogdaboitempo.com.br/2020/03/20/judithbutler-sobre-o-covid-19-o-capitalismo-tem-seus-limites/. Acesso em 15 jun. 2020.

BUTLER, Judith. Quadros de guerra: quando a vida é passível de luto?. Rio de Janeiro: Civilização Brasileira, 2016.

CGI.BR; NIC.BR; CENTRO REGIONAL DE ESTUDOS PARA O DESENVOLVIMENTO DA SOCIEDADE DA INFORMAÇÃO (CETIC.BR). Pesquisa sobre o uso das tecnologias de informação e comunicação nos domicílios brasileiros: TIC Domicílios 2019.

2019.Disponível em:

https://www.cetic.br/media/analises/tic_domicilios_2019_coletiva_imprensa.pdf . Acesso em: 15 jun. 2020.

COLLINS, Lois. Will protests change how contact tracing for COVID-19 works?: finding those who were potentially exposed to the coronavirus is key to stopping the spread, according to experts. Deseret News. 2020. Disponível em:

https://www.deseret.com/indepth/2020/6/19/21292151/protests-salt-lake-county-johnshopkins-university-health-covid-19-contact-tracing. Acesso em: 15 jun. 2020.

COMITÊ EUROPEU PARA PROTEÇÃO DE DADOS. Diretrizes 4/2020 sobre a utilização de dados de localização e meios de rastreio de contactos no contexto do surto de COVID-19: adotadas em 21 de abril de 2020. Disponível em:

https://edpb.europa.eu/sites/edpb/files/files/file1/edpb_guidelines_20200420_contact _tracing_covid_with_annex_pt.pdf. Acesso em: 15 jun. 2020.

CORRÊA, Sonia. De volta ao de sempre: segregação por sexo/gênero como medida de contenção da Covid-19. Sexuality Policy Watch. 2020. Disponível em:

https://sxpolitics.org/ptbr/de-volta-ao-de-sempre-segregacao-por-sexo-genero-comomedida-de-contencao-da-covid-19/10296. Acesso em: 15 jun. 2020. 
DATOS PROTEGIDOS. ¿Por qué lo publicado por Interferencia.cl implica una grave transgresión a la privacidad y al derecho a la protección de los datos personales?. 14 de maio de 2020. Disponível em: https://datosprotegidos.org/por-que-lo-publicadopor-interferencia-cl-implica-una-grave-transgresion-a-la-privacidad-y-al-derecho-a-laproteccion-de-los-datos-personales/. Acesso em: 15 jun. 2020.

DAVIS, Sara L. M. Contact tracing apps: extra risks for women and marginalized groups. Health and Human Rights Journal, Apr. 2020. Disponível em:

https://www.hhrjournal.org/2020/04/contact-tracing-apps-extra-risks-for-women-andmarginalized-groups/. Acesso em: 15 jun. 2020.

DE MONTJOYE, Y; HIDALGO, C; VERLEYSEN, M. et al. Unique in the crowd: the privacy bounds of human mobility. Scientific Reports, v. 3, n. 1376, 2013.

DEL CASTILLO, Aída Ponce. 'Covid-19 contact-tracing apps: how to prevent privacy from becoming the next victim'. In: EUROPEAN ECONOMIC, EMPLOYMENT AND SOCIAL POLICY. ETUI policy brief - 5/2020. 2020. Disponível em: etui.org/publications/policy-briefs/european-economic-employment-and-socialpolicy/covid-19-contact-tracing-apps-how-to-prevent-privacy-from-becoming-thenext-victim. Acesso em: 22 jun. 2020.

DIAS, Tatiana. Vigiar e lucrar: nós identificamos dois clientes dos dados de localização "anônimos" vendidos pela Vivo. The Intercept Brasil, 13 abr. 2020. Disponível em: https://theintercept.com/2020/04/13/vivo-venda-localizacao-anonima/. Acesso em: 2020.

DONEDA, Danilo. A proteção de dados em tempos de coronavírus: a LGPD será um elemento fundamental para a reestruturação que advirá após a crise. Jota, 25 mar. 2020. Disponível em: https://www.jota.info/opiniao-e-analise/artigos/a-protecao-dedados-em-tempos-de-coronavirus-25032020. Acesso em: 15 maio 2020.

DONEDA, Danilo. Da privacidade à proteção de dados pessoais: elementos da lei geral de proteção de dados. 2. ed. São Paulo: Thomson Reuters Brasil, 2019.

EUROPEAN COMMISSION. Communication from the Commission to the European Parliament and the Council: guidence on the regulation on a framework for the free flow of non-personal data in the European Union. Bruxelas: [s.n.], 2019. Disponível em: https://eur-lex.europa.eu/legal-content/EN/TXT/?uri=COM:2019:250:FIN. Acesso em: 30 maio 2020.

EUROPEAN DATA PROTECTION BOARD. Guidelines 04/2020 on the use of location data and contact tracing tools in the contexto of the COVID-19 outbreak. Bruxelas: [s.n.], 2020. Disponível em: https://edpb.europa.eu/our-work-tools/ourdocuments/usmernenia/guidelines-042020-use-location-data-and-contact-tracing_en. Acesso em: 15 jul. 2020.

GASSER, Urs; IENCA, Marcello; SCHEIBNER, James; SLEIGH, Joanna; VAYENA, Effy. Digital tools against COVID-19: framing the ethical challenges and how to address them. 2020. Disponível em: https://www.researchgate.net/publication/340859770_Digital_tools_against_COVID19_Framing_the_ethical_challenges_and_how_to_address_them/citation/download. Acesso em: 22 maio 2020. 
GOVERNO DE SÃO PAULO. Plano São Paulo. Disponível em:

https://www.saopaulo.sp.gov.br/planosp/simi/ Acesso em: 15 jun. 2020.

HART, V. et al. Outpacing the virus: digital response to containing the spread of COVID-19 while mitigating privacy risks. Safra Center for Ethics, 2020. Disponível em: https://ethics.harvard.edu/outpacing-virus. Acesso em: 15 jun. 2020.

INLOCO. Privacy policy. 2020. Disponível em: https://public.inloco.ai/en/privacypolicy\#covid Acesso em: 15 jun. 2020.

KIND, Carly. Exit through the App Store?. Ada Lovelace Institute. 2020. Disponível em: https://www.adalovelaceinstitute.org/our-work/covid-19/covid-19-exit-through-theapp-store/ Acesso em: 15 jun. 2020.

KITCHIN, Rob. Civil liberties or public health, or civil liberties and public health?. using surveillance technologies to tackle the spread of COVID-19. Space and Polity, p. 1-20, 3 Jun. 2020. Disponível em: http://dx.doi.org/10.1080/13562576.2020.1770587. Acesso em: 22 maio 2020.

KWON, Jake; HOLLINGSWORTH, Julia. Virus outbreak linked to Seoul clubs popular with LGBT community stokes homofobia. CNN, 13 maio 2020. Disponível em: https://edition.cnn.com/2020/05/12/asia/south-korea-club-outbreak-intl-hnk/index.htl Acesso em: 15 jun. 2020.

KWON, Jen. A new coronavirus cluster linked to Seoul nightclubs is fueling homofobia. CBS News,12 maio 2020. Disponível em:

https://www.cbsnews.com/news/south-korea-coronavirus-cluster-linked-to-seoulnightclubs-fueling-homophobia-fears-gay-men/ Acesso em: 15 jun. 2020.

LARANJEIRAS, Antônio Heleno Caldas. Mapas do coronavírus: desafios e direções. Outras palavras, 31 mar. 2020. Disponível em:

https://outraspalavras.net/outrapolitica/mapas-do-coronavirus-desafios-e-direcoes/ Acesso em: 15 jun. 2020.

LEONG, Kan-lon et al. Contact tracing in healthcare digital ecosystems for infectious disease control and quarantine management. IEEE International Conference on Digital Ecosystems and Technologies 2009. Disponível em:

http://repository.um.edu.mo/handle/10692/14361?mode=full\&submit_simple=Show+f ull+item+record. Acesso em: 15 jun. 2020

MARQUES, Humberto. Ameaças contra indígenas por 'levarem coronavírus' geram tensão em aldeias de MS. Jornal Midiamax, 24 jul. 2020. Disponível em:

https://www.midiamax.com.br/cotidiano/2020/gravacoes-com-acusacoes-e-ameacascontra-indigenas-por-levar-coronavirus-a-cidade-de-ms-geram-tensao-em-aldeias. Acesso em: 15 jun. 2020.

MORALES, Felipe Vargas. Protegerlos de hostigamientos o tener información para ayudarlos: el debate sobre el acceso a datos de los pacientes. Emol.com., 23 abr. 2020. Disponível em:

https://www.emol.com/noticias/Nacional/2020/04/23/984003/Gobierno-Datos-

Alcaldes-Coronavirus.html. Acesso em: 15 jun. 2020. 
MORLEY, Jessica; COWLS, Josh; TADDEO, Mariarosaria; FLORIDI, Luciano. Ethical Guidelines for SARS-CoV-2 Digital Tracking and Tracing Systems, 2020. Disponível em: https://ssrn.com/abstract=3582550 ou http://dx.doi.org/10.2139/ssrn.3582550 Acesso em: 22 maio 2020.

MULHOLLAND, Caitlin. Dados pessoais sensíveis e a tutela de direitos fundamentais: uma análise à luz da lei geral de proteção de dados (Lei 13.709/18). Revista de Direitos e Garantias Fundamentais, v. 19, p. 159-180, 2018.

NARAYANAN, Arvind; FELTEN, Edward W. No Silver Bullet: De-identification Still Doesn't Work. 9 de julho de 2014. Disponível em: http://randomwalker.info/publications/no-silver-bullet-de-identification.pdf Acesso em 15 maio 2020.

NUFFIELD COUNCIL ON BIOETHICS. Nuffield council on bioethics, ethical considerations in responding to the COVID-19 pandemic. 2020. Disponível em: www.nuffieldbioethics.org/assets/pdfs/Ethical-considerations-in-responding-to-the COVID-19-pandemic.pdf/. Acesso em: 22 maio 2020.

OHM, Paul. Broken promises of privacy: responding to the surprising failure of anonymization. UCLA Law Review, n. 57, p. 1701-1777, 2010.

OLIVEIRA, I. J. de. A linguagem dos mapas: utilizando a cartografia para comunicar. Temporis (ação) (UEG), v. 1, n. 8, p. 37-62, 2005. Disponível em: https://files.cercomp.ufg.br/weby/up/215/o/OLIVEIRA_Ivanilton_Jose_linguagem_do s_mapas.pdf. Acesso em: 15 jun. 2020.

OLIVEIRA, Ubirajara et al. Modelagem da vulnerabilidade dos povos indígenas no Brasil ao Covid-19. 2020. Disponível em: https://drive.google.com/file/d/1H596_oDmOGf4mOTziHGIrbYM17PdycVj/view. Acesso em: 15 jun. 2020.

O'NEIL, Cathy. Weapons of math destruction: how big data increases inequality and threatens democracy. Broadway Books, 2016.

OUTRIGHT ACTION INTERNATIONAL. Vulnerability amplified: the impact of the

COVID-19 pandemic on LGBTIQ people. New York: OutRight Action International, 2020. Disponível em:

https://outrightinternational.org/sites/default/files/COVIDsReportDesign_FINAL_LR_O .pdf. Acesso em: 15 jun. 2020.

PREFEITURA MUNICIPAL DE MIRANDA. Miranda contabiliza seis casos positivos para a Covid-19. 21 de julho de 2020. Disponível em: https://miranda.ms.gov.br/mirandacontabiliza-seis-casos-positivos-para-covid-19/. Acesso em: 15 jun. 2020.

RODOTÀ, Stefano. A vida na sociedade da vigilância: a privacidade hoje. Rio de Janeiro: Renovar, 2008.

RODOTÀ, Stefano. Il mondo nella rete: quali i diritti, quali i vincoli. Roma: Laterza \& Figli - Gruppo Editoriale L’Espresso, 2019. 
TAYLOR, Linnet. No place to hide?: the ethics and analytics of tracking mobility using African mobile phone data. Environment and Planning D, n. 34, 2015.

TAYLOR, Linnet. Safety in numbers?: group privacy and big data analytics in the developing world. In: TAYLOR, Linnet; FLORIDI, Luciano; SLOOT, Bart van Der (ed.). Group privacy: new challenges of data technologies. Cham, Suíça: Springer International Publishing, 2017. p. 13-36. (Philosophical Studies Series).

TAYLOR, Linnet; FLORIDI, Luciano; SLOOT, Bart van Der. Introduction: a new perspective on privacy. In: TAYLOR, Linnet; FLORIDI, Luciano; SLOOT, Bart van Der (ed.). Group privacy: new challenges of data technologies. Cham, Suíça: Springer International Publishing, 2017. p. 1-12. (Philosophical Studies Series).

TEFFÉ, Chiara Spadaccini de; GABRIEL, Anderson de Paiva. Ferramentas tecnológicas e controle da pandemia: quais os limites para o emprego da tecnologia?. Jota, 14 jun. 2020. Disponível em: https://www.jota.info/opiniao-e-analise/colunas/juizhermes/ferramentas-tecnologicas-e-controle-da-pandemia-14062020. Acesso em: 20 jun. 2020.

SARAMAGO, José. As intermitências da morte. São Paulo: Companhia das Letras, 2005.

SARLET, Ingo Wolfgang. Os direitos fundamentais sociais na Constituição de 1988. In: SARLET, Ingo Wolfgang (Org.). Direito Público em tempos de crise: estudos em homenagem a Ruy Ruben Ruschel. Porto Alegre: Livraria do Advogado, 1999.

SUASSUNA, Ariano. Auto da Compadecida. 10. ed. São Paulo: Agir Editora, 1973.

WANG, Huandong; GAO, Chen; LI, Yong; WANG, Gang; JIN, Depeng; SUN, Jingbo. Deanonymization of mobility trajectories: dissecting the gaps between theory and practice. In: 2018 NETWORK AND DISTRIBUTED SYSTEM SECURITY SYMPOSIUM, 2018, San Diego, CA, USA. Electronic proceedings... DOI:

http://dx.doi.org/10.14722/ndss.2018.23211. Acesso em: 15 jun. 2020.

WINNER, Langdon. Do artifacts have politics?. Daedalus, v. 109, n. 01, p. 121-136, 1980. Disponível em: https://www.cc.gatech.edu/ beki/cs4001/Winner.pdf. Acesso em: 15 jun. 2020.

ZANATTA, Rafael A. Perfilização, discriminação e direitos: do Código de Defesa do Consumidor à Lei Geral de Proteção de Dados Pessoais. 20--? Disponível em: https://www.researchgate.net/publication/331287708_Perfilizacao_Discriminacao_e_ Direitos_do_Codigo_de_Defesa_do_Consumidor_a_Leei_Geral_de_Protecao_de_Dad os_Pessoais. Acesso em: 15 jun. 2020. 